\title{
The Impact of Various Promotional Activities on Ebola Prevention Behaviors and Psychosocial Factors Predicting Ebola Prevention Behaviors in the Gambia Evaluation of Ebola Prevention Promotions
}

\author{
Anna E. Gamma ${ }^{\dagger}$, Jurgita Slekiene ${ }^{\dagger}\left[\right.$ and Hans-Joachim Mosler ${ }^{*}+\dagger$ \\ EAWAG, Swiss Federal Institute of Aquatic Science \& Technology, Ueberlandstrasse 133, CH-8600 Duebendorf, \\ Switzerland; anna.gamma@gmx.net (A.E.G.); jurgita.slekiene@eawag.ch (J.S.) \\ * Correspondence: mosler@eawag.ch \\ + These authors contributed equally to this work.
}

Received: 11 April 2019; Accepted: 31 May 2019; Published: 6 June 2019

\begin{abstract}
The outbreak of the Ebola virus disease (EVD) from 2014 to 2016 is over. However, several outbreaks of contagious diseases have already arisen and will recur. This paper aims to evaluate the effectiveness of EVD prevention promotions in the Gambia and to assess the psychosocial factors that steer three behaviors: handwashing with soap, calling the Ebola Hotline, and not touching a person who might be suffering from EVD. In 2015, data were gathered from 498 primary care providers. The questionnaire was based on psychosocial factors from the risks, attitudes, norms, abilities, and self-regulation (RANAS) model. Three promotional activities were significantly associated with psychosocial factors of handwashing and, thus, with increased handwashing behavior: the home visit, posters, and info sheets. Norm factors, especially the perception of what other people do, had a great impact on handwashing with soap and on calling the Ebola Hotline. The perceived certainty that a behavior will prevent a disease was a predictor for all three protection behaviors. Commitment to the behavior emerged as especially relevant for the intention to call the Ebola Hotline and for not touching a person who might be suffering from EVD. Health behavior change programs should rely on evidence to target the right psychosocial factors and to maximize their effects on prevention behaviors, especially in emergency contexts.
\end{abstract}

Keywords: Ebola virus disease (EVD) prevention; behavior change; psychosocial factors; RANAS model; handwashing with soap; emergencies and outbreaks; mediation analysis

\section{Introduction}

During the previous outbreak of Ebola virus disease (EVD) in West Africa, 28,646 cases were confirmed, probable, or suspected, and 11,323 deaths were reported [1]. The ebola virus disease is a severe illness with a mortality rate between $25 \%$ and $90 \%$ and an average fatality rate of around $50 \%$. Fruit bats (family Pteropodidae) are considered a reservoir of EVD. They spread the virus to chimpanzees, gorillas, monkeys, and humans. Human-to-human transmission occurs via blood, body fluids, contaminated objects, handling of dead bodies during funerals, and sexual transmission after recovery [2]. Although promising effects of an EVD vaccine have recently been confirmed in Guinea [3], outbreaks of contagious diseases, such as the emerging Zika virus disease, will recur. Besides vaccines against contagious diseases, preventive behaviors play a crucial role in impeding further transmission in a population. The WHO recommends the following package of interventions to control an outbreak in general: surveillance, infection prevention, and control practices, case management, contact tracing, community engagement, social mobilization, safe burials, and a good 
laboratory service [2]. The spread of EVD was exacerbated and facilitated by weak health systems and the limited capacities of governments to monitor fluid borders [4].

Many studies have used knowledges-attitudes-practice (KAP) surveys to assess awareness of the disease. These KAP studies mostly reveal the level of knowledge of the population about Ebola [5-7], and some analyze the effects of information sources used [8]. However, evaluations of health interventions in emergency settings are rare $[9,10]$. Increasing the efficiency of public health interventions requires rigorous evidence about the effectiveness of interventions to change behavioral determinants, behaviors, and their impact on health outcomes [11,12].

In the previous outbreak of EVD in West Africa, which is a disease previously unknown in the affected population, health workers had to address disbeliefs about the disease and strong cultural traditions that contributed to the spread of the virus. These included caring for sick people at home, going to traditional healers, and being in close contact with dead bodies before the burial ceremony. Communication is a key activity during an emergency response [13], but the content of the messages should go beyond simple health information. Awareness-raising and information, both of which were crucial and essential in the affected regions, do not, on their own, necessarily lead to the desired behavior. However, they can build the foundation of a behavioral change over the long term $[14,15]$. Behaviors are based on processes in the minds of individuals, so the uptake of new protective behaviors requires either that people's mindsets are in favor of these behaviors or that they change [16]. Therefore, understanding what drives a specific behavior within a specific population or context is essential to developing effective public health interventions, and not only in an epidemic or pandemic $[17,18]$. Systematic behavioral changes, as proposed by Mosler [18], are based on research from environmental and health psychology. It first systematically assesses the psychosocial factors that steer behavior. Knowledge of the psychosocial factors underlying the desired behaviors can then guide the selection of evidence-based interventions. The final phase of systematic behavior change evaluates the effectiveness of the interventions and the mechanisms of the change [19]. The urgent need for careful evaluation of emergency hygiene promotions has been shown by Contzen and Mosler [20]. They evaluated the effect of various promotional activities on handwashing behavior as a response to a cholera outbreak in Haiti after the earthquake in 2010. The evaluation revealed that several promotional activities had negative associations with behavior, which means people who had experienced the activity reported less handwashing. This finding indicates that the activity might be not only ineffective but even counterproductive. Therefore, accurate evaluations of promotional activities are crucial to maximize their impact and to avoid unwanted effects.

\subsection{The Current Study}

The month before this survey took place in Gambia, the local collaborator, Concern Universal, together with other local partners, implemented four the Ebola prevention promotions: Household visits, posters with information about EVD at public places, EVD information sheets for households, and hygiene kits. The household visits were used to present transmission routes, symptoms of Ebola, and preventive behaviors. The poster displayed the symptoms of Ebola, requests to wash hands with soap and water, and to report signs of Ebola to a health facility. The information sheet contained instructions about signs and symptoms of Ebola, contamination pathways, and prevention measures. The hygiene kits included soap, bleach, material for a tippy tap (www.tippytap.org/the-tippy-tap), cups, a bucket, and a flyer about Ebola. This study aimed to evaluate these Ebola prevention promotions in Gambia. The main objective was to reveal whether the promotions successfully tackled key psychosocial determinants of the prevention behaviors, because this is a precondition for the effectiveness of health promotions and enables understanding of why a promotional activity was effective. Furthermore, it was possible to show which of the key determinants had not been tackled so far by promotional activities. Another objective was to identify the key determinants of the three EVD preventive behaviors of interest: handwashing with soap, calling the Ebola Hotline, and not touching a person who might be suffering from EVD. The findings of this study can be used to improve the EVD 
response activities that have already been implemented by including the key psychosocial determinants that have not been addressed so far and that are, therefore, promising targets for increasing EVD prevention behaviors.

\subsection{The RANAS Model of Behavior Change}

The risks, attitudes, norms, abilities, and self-regulation (RANAS) approach was developed to predict health behavior in developing countries [18]. It offers an effective instrument for identifying psychosocial factors in the water, sanitation, and hygiene (WASH) and health sectors. It has been applied to answer the research questions of the present study. The RANAS approach also enables the effectiveness of promotional activities to be evaluated by looking at their underlying mechanisms. This is done by analyzing whether the interventions successfully tackled the key behavioral factors or not. The applicability of the approach has been demonstrated in various studies [20-23].

The RANAS model includes five blocks of factors. Risk factors include factual knowledge about the transmission of a disease, methods of prevention, personal consequences, perceived vulnerability, and the perceived severity of contracting a disease. Attitude factors include beliefs about the costs and benefits of a particular behavior and feelings associated with the behavior. Norm factors, such as the perception of what others are doing, others' disapproval, and personal importance, relate to perceived social influence. Ability factors include people's confidence in the performance of a particular behavior. Self-regulation factors include the management of conflicting goals, distracting cues and barriers, commitment, and remembering the behavior.

\subsection{The Preventive Behaviors during an Ebola Outbreak}

The preventive behaviors during an EVD outbreak include safe burial, regular handwashing with soap, reporting suspected EVD cases to the National Ebola Hotline or a health facility, and not touching a sick person [2]. Because no cases of EVD occurred in Gambia, calling the Ebola Hotline to report a suspected case and not touching someone who might be suffering from EVD could not be measured directly. Therefore, behavioral intention and behavioral willingness were examined for these behaviors.

This paper presents cross-sectional study results from an EVD response survey in Gambia and addresses four research questions.

Which are the crucial psychosocial determinants of handwashing with soap at key times under the threat of EVD?

Which are the crucial psychosocial determinants of the intention to call the Ebola Hotline to report a suspected case of EVD?

Which are the crucial psychosocial determinants of the intention not to touch someone who might be suffering from EVD?

Which promotional activities affect which psychosocial factors and influence the preventive behaviors through these factors?

\section{Materials and Methods}

\subsection{Research Area}

The Republic of the Gambia is one of Africa's smallest countries. It is surrounded by Senegal except for its coastline on the Atlantic Ocean at its western end. The Gambia is divided into five administrative regions and one city. The study area consisted of two regions in which Ebola promotion activities were conducted, which included the West Coast Region, comprising 19 communities, and the Lower River Region, comprising 22 communities. Data were collected in all these communities. These are areas with large volumes of passenger transport and goods transport from all sides (Senegal to the north and south and Guinea Bissau to the south). The Gambia trades extensively with neighboring countries 
through markets that involve large volumes of trucks, passenger vehicles, and other travelers crossing its borders in both directions.

\subsection{Participants}

The sample includes data from 498 respondents. The interviews were conducted with the member of the household who is responsible for the care of the sick. The household selection was based on random-route sampling, according to the protocol defined by Hoffmeyer-Zlotnik [24]. Following this protocol, the interviewers were sent to different places in the community and instructed to include every third household they encountered on their way. Interventions were implemented in all the communities, so most people living there should have experienced the interventions.

\subsection{Procedure}

The study was conducted in the Gambian households in May and June 2015. A quantitative cross-sectional survey was conducted with structured face-to-face interviews using a paper-and-pencil format. Each interview took around one hour and was held in one of the local languages: Jola, Mandinka, or Fula. A team of 10 local health sector employees were recruited as interviewers. They attended five days of intensive training, during which they learned about the study, its goals, and the theoretical background of the questionnaire. The data collectors practiced interview techniques and the translation of the questions into the local languages. Two supervisors and the local collaborator coordinated and corrected the interviews and accompanied the data collectors in the field during the entire period of the data collection. Each data collector conducted the survey in those communities in which he or she was not working as health workers. All study participants provided their written informed consent prior to the interviews. The study received ethical approval from the School of Medicine and its allied Health Sciences Research and Publication Committee at the University of Gambia.

\subsection{Promotional Activities}

In the months before the survey took place, the local collaborator, Concern Universal, together with other local partners implemented four promotion activities to help prevent an EVD outbreak in Gambia. The respondents were asked if they had experienced the Ebola prevention promotions or not.

\subsection{Questionnaire and Measures}

A structured questionnaire was developed and pre-tested for this study. The questionnaire was based on the psychosocial factors of the RANAS model [18]. Most of the questions were measured using 5-point Likert scales, which were pretested and extensively discussed and trained with the interviewers. The questionnaire covered the following elements: socio-demographic characteristics, psychosocial factors for handwashing with soap, self-reported handwashing frequencies, the intention to follow the prevention instructions (to call the Ebola Hotline and not to touch a person who might be suffering from EVD), and corresponding psychosocial factors, measures of socio-economic status, remembered promotion activities, and attitudes toward them.

Additionally, frequency of communication about the Ebola Hotline was included because talking frequency is an important determinant of whether a person will change a certain behavior or not [25]. Various studies have confirmed that communication plays an essential role in a health-related behavioral change [26].

The questionnaire was tested at the end of the interviewers' training to verify its applicability.

\subsection{Handwashing with Soap at Key Times}

To include the data from all respondents, only the handwashing moments after defecation and before eating were used for analysis. The data collectors asked the respondents how often they washed 
hands after defecation and before eating. Answers were assessed on a 5-point rating scale from (almost) never to (almost) every time. A mean score was built with the two handwashing questions (Cronbach's alpha $\alpha=0.75)$.

\subsection{Intention to Follow Prevention Instructions}

The intention to follow EVD prevention instructions, reporting a suspected EVD case to the Ebola Hotline and not touching sick people, was operationalized through behavioral intention and behavioral willingness. Two direct questions were asked using self-reported 5-point Likert scales, from 1 (not at all) to 5 (very strongly) for calling the Ebola Hotline and from 1 (not at all willing) to 5 (very willing) for not touching sick people (Cronbach's alpha $\alpha=0.60$, see Table 1 ). The combined means of these items were used for the analyses.

Table 1. Questions to measure the intention to follow the two prevention behaviors.

\begin{tabular}{ll}
\hline Factor & Wording \\
\hline & $\begin{array}{l}\text { How strongly do you intend to call the National Ebola Hotline if you have a } \\
\text { person with suspected Ebola in your household? } \\
\text { Now we would like to ask you to imagine yourself in a certain situation. }\end{array}$ \\
$\begin{array}{l}\text { Intention to call the } \\
\text { Ebola Hotline }\end{array}$ & $\begin{array}{l}\text { Suppose you have been at the market the whole day to sell vegetables. } \\
\text { At the end of the day, you go home, and you find a member of your family } \\
\text { who is vomiting, and the vomit contains blood, which could be a symptom } \\
\text { of Ebola. In those circumstances, how willing would you be to call the Ebola }\end{array}$ \\
& Hotline and report the suspected Ebola case in your household? \\
\hline & $\begin{array}{l}\text { How strongly do you intend to not touch a sick person who might suffer } \\
\text { from Ebola in your household? }\end{array}$ \\
Intention not to touch & $\begin{array}{l}\text { Now we would like to ask you to imagine yourself in a certain situation. } \\
\text { Suppose you have been at the market the whole day to sell vegetables. } \\
\text { someone who might } \\
\text { be suffering from EVD }\end{array}$ \\
At the end of the day, you go home, and you find a member of your family \\
who is vomiting, and the vomit contains blood, which can be a symptom for \\
Ebola. In those circumstances, how willing would you be to not touch the \\
sick person, which reduces the risk of contracting Ebola?
\end{tabular}

\subsection{Psychosocial Factors}

The psychosocial factors were measured as proposed in the RANAS model [18]. A description of the items can be found in Table A1 in Appendix A. Each factor was measured with at least one item. In cases where two or more items were used to measure a factor, the mean of these items was used for the analyses. The how-to-do knowledge for calling the Ebola Hotline was operationalized with a dichotomous item with responses coded as zero (did not know the number of the Ebola Hotline) or one (knew the number).

\subsection{Statistical Analyses}

Statistical analyses of the data were calculated with IBM SPSS 22 Statistics software (IBM SPSS Statistics for Windows, Version 22.0, IBM Corp., Armonk, NY, USA). Frequencies, multiple linear regression, and multiple mediation models were computed using the SPSS PROCESS macro [27]. Only psychosocial factors that were significant predictors within the multiple linear regression analyses were included in mediation models as mediators $(\mathrm{M})$. Promotion activities were included as predictors $(\mathrm{X})$ and EVD preventive behaviors as outcomes $(\mathrm{Y})$ in parallel multiple mediator models. The specific indirect $(\mathrm{a} \times \mathrm{b})$, direct $\left(\mathrm{c}^{\prime}\right)$, and total effects (c) were calculated. A specific indirect effect is the effect of promotion activity via psychosocial factors on EVD preventive behaviors. The direct effect is the effect of the promotion activity on the EVD preventive behavior when the mediators (psychosocial factors) are not present in the model ( $\mathrm{X}$ on $\mathrm{Y}$ independent of $\mathrm{M})$. The total effect $(\mathrm{c})$ is the sum of the specific indirect effect $(\mathrm{a} \times \mathrm{b})$ and the direct effect $\left(\mathrm{c}^{\prime}\right)$ (Figure $\left.\mathrm{S} 1\right)$. 


\section{Results}

In terms of gender, $434(87.3 \%)$ of the respondents were female, and $63(12.7 \%)$ were male. The reported age of the respondents ranged from 15 to 80 years $(M=35.89, \mathrm{SD}=13.22)$. On average, 12 people lived in the same household $(\mathrm{SD}=7.68)$, which was defined as living in the same compound. The mean number of children under the age of five in the study households was three (SD $=1.92)$.

\subsection{Reach of the Promotional Activities}

The analyses included four activities that promoted the preventive behaviors (see Table 2). The channel with the highest reach was the household visit, which reached $67 \%$ of respondents, followed by the poster at $63 \%$. Nearly half of the respondents, $47 \%$, received at least two items of the hygiene kit, and 39\% of the respondents knew the Ebola information sheet.

Table 2. Overview of promotion activities and percentage of people who experienced the promotion.

\begin{tabular}{|c|c|c|}
\hline Ebola Prevention Promotion & Description & $\%$ \\
\hline Household visit & $\begin{array}{l}\text { Main goal: Discuss the signs and symptoms of Ebola, } \\
\text { the transmission routes, and hygiene behavior for } \\
\text { Ebola prevention. }\end{array}$ & $67 \%$ \\
\hline $\begin{array}{l}\text { Poster with information about } \\
\text { EVD at public places }\end{array}$ & $\begin{array}{l}\text { Main goal: Disseminate key messages how to protect } \\
\text { yourself from Ebola (handwashing with soap and } \\
\text { water), reporting the Ebola case to the Ebola Hotline, } \\
\text { and the symptoms of Ebola (headache, vomiting, } \\
\text { fever, joint pain, and bleeding). }\end{array}$ & $63 \%$ \\
\hline $\begin{array}{l}\text { Ebola information sheet for } \\
\text { the household }\end{array}$ & $\begin{array}{l}\text { Main goal: Disseminate key messages how to protect } \\
\text { yourself from Ebola (handwashing with soap and } \\
\text { water), reporting the Ebola case to a health facility, } \\
\text { and the symptoms of Ebola (headache, vomiting, } \\
\text { fever, joint pain, and bleeding). }\end{array}$ & $39 \%$ \\
\hline Hygiene kits & $\begin{array}{l}\text { Included soap, bleach, and material for a tippy tap, } \\
\text { cups, a bucket, and a flyer about Ebola (only counted } \\
\text { if someone received at least two items) }\end{array}$ & $47 \%$ \\
\hline
\end{tabular}

\subsection{Psychosocial Factors Influencing Ebola Prevention Behaviors}

Multiple regression analysis was conducted to reveal the influence of sociodemographic variables on the three behaviors (see Table A2 in Appendix A). However, the explained variance was very low, so these results were not taken into account.

On average, respondents stated that they wash their hands with soap and water at most key times. Handwashing after using the toilet was more frequently practiced than handwashing before eating. For the analysis, the two key times for handwashing with soap were combined (see Table 3). On average, the respondents said that they were willing and that they strongly intended to call the Ebola Hotline if there was an EVD case in the household. The same was found for the intention not to touch someone who might be suffering from EVD (see Table 3). However, the results showed that $89.6 \%$ of the respondents did not know the number of the Ebola Hotline.

Table 3. Means (M) and standard deviations (SD) of handwashing, the intention to call the Ebola Hotline, and the intention not to touch someone who might be suffering from Ebola.

\begin{tabular}{cccc}
\hline Key Time/Dependent Variable & N & M & SD \\
\hline After using the toilet & 495 & 4.51 & 0.74 \\
Before eating & 496 & 4.26 & 0.99 \\
Combined handwashing variable & 496 & 4.38 & 0.78 \\
Calling the Ebola hotline & 497 & 4.11 & 0.78 \\
Not touching & 491 & 4.12 & 0.94 \\
\hline
\end{tabular}




\subsection{Handwashing with Soap and Water}

A multiple linear regression analysis was used to answer the first research question. The analysis revealed that six psychosocial factors significantly predicted the handwashing frequency (see Table 4). The model explains $48.5 \%$ of the variance in the self-reported handwashing frequency.

Table 4. Linear regression analysis for psychosocial factors explaining handwashing with soap and water.

\begin{tabular}{ccccc}
\hline Factor Group & Psychosocial Factors & M (SD) & $p$-Value & $\beta$ \\
\hline \multirow{4}{*}{ Risk factors } & Community vulnerability & $2.86(1.51)$ & 0.563 & 0.035 \\
& Vulnerability & $2.37(1.48)$ & 0.114 & 0.098 \\
& Severity & $4.37(0.88)$ & 0.134 & 0.069 \\
& Cealth knowledge & $18.93(4.36)$ & 0.746 & 0.013 \\
& Conditional vulnerability (not protecting) & $3.88(1.33)$ & 0.001 & $0.149^{* * *}$ \\
& Conditional vulnerability (protecting) & $2.11(1.26)$ & 0.535 & -0.023 \\
\hline \multirow{2}{*}{ Attitude factors } & Cost belief (effort) & $1.27(0.73)$ & 0.051 & -0.087 \\
& Cost belief (time) & $1.41(0.86)$ & 0.782 & -0.013 \\
& Cost belief (costs) & $2.44(1.19)$ & 0.004 & $0.124^{* *}$ \\
& Cost belief (distance) & $1.61(0.99)$ & 0.586 & -0.022 \\
Norm factors & Feelings (like) & $4.40(0.71)$ & 0.425 & 0.042 \\
& Response belief & $4.21(0.89)$ & 0.008 & $0.123^{* *}$ \\
\hline \multirow{3}{*}{ Self-regulation } & Others' behavior & $4.12(0.76)$ & 0.000 & $0.305^{* * *}$ \\
factors & Others'(dis)approval & $4.26(0.67)$ & 0.007 & $0.123^{* *}$ \\
& Personal importance & $4.31(0.65)$ & 0.041 & $0.106^{*}$ \\
\hline \multirow{2}{*}{ Ability factors } & How-to-do knowledge & $3.69(0.70)$ & 0.075 & 0.074 \\
& Confidence in performance & $4.31(0.82)$ & 0.259 & 0.058 \\
& Confidence in performance (water) & $1.77(1.16)$ & 0.893 & -0.006 \\
& Confidence in performance (soap) & $2.48(1.20)$ & 0.885 & -0.007 \\
\hline & Confidence in performance (time) & $1.49(1.01)$ & 0.923 & -0.005 \\
& Confidence in performance (distance) & $4.07(0.89)$ & 0.174 & -0.068 \\
\hline
\end{tabular}

Note: ${ }^{*} p \leq 0.05,{ }^{* *} p \leq 0.01,{ }^{* * *} p \leq 0.001$. Adjusted $\mathrm{R}^{2}=0.485 . \quad N=422$.

Conditional vulnerability (not protecting) $(\beta=0.149$ ), which means thinking that the probability of an infection with EVD is high if they do not protect themselves with regular handwashing, was significantly associated with handwashing. Cost belief $(\operatorname{costs})(\beta=0.124)$, which means thinking that always washing hands with soap is expensive, was associated with increased handwashing, as was the Response belief $(\beta=0.123)$. This means the perceived certainty that always washing hands with soap and water prevents diseases like EVD or diarrhea. Furthermore, all three norm factors were significantly related with higher handwashing frequency: Others' behavior $(\beta=0.305)$, which means the perception that other family members and people in the village wash hands with soap and water. Others' (dis)approval $(\beta=0.123)$ means that people who are important to them at home or in the village approve of handwashing with soap and water and personal importance $(\beta=0.106)$ means the perception of handwashing as a personal obligation.

\subsection{Calling the Ebola Hotline}

To answer the second research question, a multiple linear regression analysis was calculated. Four psychosocial factors were determined as significant predictors for the intention to call the Ebola Hotline and to report a suspected EVD case in the household (see Table 5). The model explained a variance of $27.3 \%$ in the intention to call the Ebola Hotline and report a suspected EVD case. A higher intention to call the Ebola Hotline was significantly related with Response belief $(\beta=0.195)$, which 
means study participants who think that calling the Ebola Hotline will help the person who might be suffering from Ebola. Then, others' behavior in the household $(\beta=0.108)$, which means respondents who think that many people from their own household would call the Ebola Hotline, contributed significantly to explaining the intention to call the Ebola Hotline. Feeling committed to calling the Ebola Hotline $(\beta=0.226)$ was the most important predictor of the intention to call the Ebola Hotline. Communication $(\beta=0.133)$, which means that people who talk often about the Ebola Hotline are more likely to have a higher intention to call the Ebola Hotline than people who talk less often about it, was also a significant predictor.

Table 5. Linear regression analysis for psychosocial factors explaining the intention to call the Ebola Hotline and report a suspected EVD case.

\begin{tabular}{clccc}
\hline Factor Group & \multicolumn{1}{c}{ Psychosocial Factors } & M (SD) & $\boldsymbol{p}$-Value & $\boldsymbol{\beta}$ \\
\hline \multirow{4}{*}{ Risk factors } & Community vulnerability & $2.76(1.52)$ & 0.191 & 0.089 \\
& Vulnerability & $2.30(1.44)$ & 0.749 & -0.022 \\
& Severity & $4.30(0.92)$ & 0.400 & -0.040 \\
& Health knowledge & $18.87(4.43)$ & 0.113 & 0.070 \\
\hline \multirow{2}{*}{ Attitude factor } & Response belief & $4.18(0.85)$ & 0.000 & $0.195^{* * *}$ \\
\hline \multirow{2}{*}{ Norm factors } & Others' behavior household & $4.10(1.18)$ & 0.021 & $0.108^{*}$ \\
& Others' (dis)approval household & $4.28(0.60)$ & 0.630 & 0.027 \\
& Others' (dis)approval village & $4.32(0.57)$ & 0.329 & 0.047 \\
& Personal importance & $4.21(0.64)$ & 0.060 & 0.096 \\
\hline \multirow{2}{*}{ Ability factors } & How-to-do knowledge & $n$. a. & 0.845 & 0.008 \\
& Confidence in performance & $4.20(0.84)$ & 0.751 & -0.014 \\
\hline Self-regulation factors & Commitment & $4.45(0.61)$ & 0.000 & $0.226^{* * *}$ \\
\hline Additional factor & Communication & $3.06(1.38)$ & 0.002 & $0.133^{* *}$ \\
\hline
\end{tabular}

\subsection{Not Touching a Person Who Might be Suffering from EVD}

To answer the third research question, another multiple linear regression analysis was calculated. This regression analysis revealed that five psychosocial factors significantly predicted the intention not to touch someone who might be suffering from EVD (see Table 6). The psychosocial factors explained $17.1 \%$ of the variance of the intention not to touch someone who might be suffering from EVD.

Table 6. Linear regression analysis for psychosocial factors explaining the intention to not touch someone who might be suffering from EVD.

\begin{tabular}{ccccc}
\hline Factor Group & Psychosocial Factors & M (SD) & $p$-Value & $\beta$ \\
\hline \multirow{3}{*}{ Risk factors } & Community vulnerability & $2.76(1.51)$ & 0.242 & 0.084 \\
& Perceived vulnerability & $2.28(1.44)$ & 0.875 & -0.011 \\
& Perceived severity & $4.29(0.92)$ & 0.719 & -0.019 \\
& Health knowledge & $19.01(4.30)$ & 0.029 & $0.101^{*}$ \\
\hline Attitude factor & Conditional vulnerability touching & $4.30(0.99)$ & 0.020 & $0.114^{*}$ \\
\hline \multirow{3}{*}{ Self-regulation factors } & Response belief & $4.22(0.85)$ & 0.002 & $0.148^{* *}$ \\
& Control not to touch & $4.27(0.71)$ & 0.686 & 0.019 \\
& Commitment to touch & $1.89(1.26)$ & 0.019 & $0.125^{*}$ \\
& Commitment not touch & $4.22(0.83)$ & 0.000 & $0.250^{* * *}$ \\
\hline
\end{tabular}

Note: ${ }^{*} p \leq 0.05,{ }^{* *} p \leq 0.01,{ }^{* * *} p \leq 0.001$. Adjusted $R^{2}=0.171 . N=467$.

A higher intention not to touch a sick person was significantly associated with respondents who have higher health knowledge about $\operatorname{EVD}(\beta=0.101)$ and with respondents who think that they are at risk if they touch a sick person who might have EVD $(\beta=0.114)$. Response belief $(\beta=0.148)$, which 
means being certain that not touching a sick person who might have EVD prevents infection with EVD, was another significant predictor of the intention not to touch someone who might be suffering from EVD.

Furthermore, commitment to touch $(\beta=0.125)$ and commitment not to touch $(\beta=0.250)$ correlated with a higher intention not to touch someone who might be suffering from EVD.

\subsection{Mediation Effects on Implemented Promotional Activities}

To answer the fourth research question, a multiple mediation analysis was conducted. The aim was to reveal which interventions were significantly associated with handwashing and the reason for this relation. This was achieved by specifying the psychosocial factors through which the promotional activities addressed the preventive behaviors. Subsequently, it can be shown which of the crucial psychosocial factors were not tackled by the promotional activities.

\subsubsection{Handwashing with Soap}

All significant predictors from the regression analysis were selected to examine the indirect and direct effects of promotional activities on handwashing by means of mediation analysis. Table 7 presents the association of the EVD promotions with the key psychosocial factors and their specific indirect, direct, and total effects on handwashing. When looking at the total effects, three promotional activities were significantly associated with increased handwashing behavior: home visit, poster, and info sheet (see Table 7). The hygiene kit did not have a significant total effect on handwashing. The relation of the promotional activities with the key psychosocial factors can explain these associations. Poster and home visits were associated with all but one key psychosocial factor. The info sheet was associated with only two key psychosocial factors, and the hygiene kit was not associated with any of the key psychosocial factors and, thus, not with handwashing either. Furthermore, all of the key psychosocial factors were significantly associated with at least one of the promotional activities.

\subsubsection{Intention to Call the Ebola Hotline}

Again, all significant predictors from the regression analysis were integrated in a mediation analysis in order to examine the indirect and direct effects of promotional activities on the intention to call the Ebola Hotline. The hygiene kit was excluded from the analysis because most items of the kit did not include information about the Ebola Hotline. Table 8 presents the association of the EVD promotions with the key psychosocial factors and their specific indirect, direct, and total effects on handwashing. When looking at the total effects, no promotional activity was significantly associated with an increased intention to call the Ebola Hotline (see Table 8). Nevertheless, relations between the promotional activities and the key psychosocial factors were significant. The poster was associated with three key psychosocial factors, the home visit was associated with all key psychosocial factors, and the info sheet was associated with two of the key psychosocial factors. Again, all of the key psychosocial factors were significantly associated with at least one of the promotional activities.

No mediation analyses were executed for not touching a sick person, for two reasons. The first was because of the low explanation by the psychosocial factors of the variance regarding the intention not to touch someone who might be suffering from EVD. The second was because not touching a sick person was not promoted in the same way as handwashing with soap and water or in the same way as calling the Ebola Hotline. 
Table 7. Mediation analysis: effects of promotional activities on self-reported handwashing via psychosocial factors (mediators).

\begin{tabular}{|c|c|c|c|c|c|c|}
\hline $\begin{array}{c}\text { Promotional } \\
\text { Activity }\end{array}$ & (a) & Psychosocial Factors/Mediators & (b) & $\begin{array}{c}\text { Specific Indirect Effect } \\
\left(a^{*} b\right) \\
95 \% \text { CL }[L L, ~ U L]\end{array}$ & Direct Effect (c') & Total Effect (c) \\
\hline Poster & $\begin{array}{c}0.55^{* * *}(0.000) \\
0.22(0.063) \\
0.37^{* * *}(0.000) \\
0.64^{* * *}(0.000) \\
0.19^{* *}(0.007) \\
0.21^{* *}(0.002)\end{array}$ & $\begin{array}{c}\text { Cond. vulnerability not protecting } \\
\text { Cost belief } \\
\text { Response belief } \\
\text { Others' behavior } \\
\text { Others' (dis)approval } \\
\text { Personal importance }\end{array}$ & $\begin{array}{c}0.13^{* * *}(0.000) \\
0.03(0.241) \\
0.14^{* * *}(0.000) \\
0.31^{* * *}(0.000) \\
0.10^{*}(0.041) \\
0.14^{* *}(0.008)\end{array}$ & $\begin{array}{c}0.07,[0.03,0.12] \\
0.01,[-0.00,0.03] \\
0.05,[0.02,0.11] \\
0.20,[0.12,0.29] \\
0.02,[0.00,0.05] \\
0.30,[0.01,0.07]\end{array}$ & ( & ( \\
\hline Hygiene kit & $\begin{array}{c}0.04(0.865) \\
-0.15(0.550) \\
0.03(0.845) \\
0.11(0.408) \\
0.01(0.948) \\
0.20(0.097)\end{array}$ & $\begin{array}{c}\text { Cond. vulnerability not protecting } \\
\text { Cost belief } \\
\text { Response belief } \\
\text { Others' behaviour } \\
\text { Others' (dis)approval } \\
\text { Personal importance }\end{array}$ & $\begin{array}{c}0.09^{* *}(0.001) \\
-0.02(0.469) \\
0.20^{* * *}(0.000) \\
0.36^{* * *}(0.000) \\
0.03(0.606) \\
0.18^{* *}(0.004)\end{array}$ & $\begin{array}{l}0.01,[-0.05,0.07] \\
0.00,[-0.01,0.03] \\
0.01,[-0.06,0.09] \\
0.04,[-0.05,0.13] \\
0.00,[-0.02,0.02] \\
0.04,[-0.01,0.13]\end{array}$ & $0.01(0.947)$ & $0.09(0.486)$ \\
\hline
\end{tabular}

Note: ${ }^{*} p \leq 0.05,{ }^{* *} p \leq 0.01,{ }^{* * *} p \leq 0.001$. Displayed are unstandardized betas and p-values. Poster: $N=401$, $R^{2}=0.50$ (b), home visit: $N=400, R^{2}=0.49(\mathrm{~b})$, info sheet: $N=401, R^{2}=0.47(\mathrm{~b})$, hygiene Kit: $N=288, R^{2}=0.42$. Number of bootstrap samples for bias-corrected bootstrap confidence intervals: 10,000. Level of confidence for all confidence intervals: $95 \%$.

Table 8. Mediation analysis: effects of promotional activities on calling the Ebola Hotline via psychosocial factors (mediators).

\begin{tabular}{|c|c|c|c|c|c|c|}
\hline $\begin{array}{l}\text { Promotional } \\
\text { Activity }\end{array}$ & (a) & $\begin{array}{c}\text { Psychosocial } \\
\text { Factors/Mediators }\end{array}$ & (b) & $\begin{array}{c}\text { Specific Indirect Effect } \\
\left(\mathrm{a}^{*} \mathrm{~b}\right) \\
95 \% \text { CL }[\mathrm{LL}, \mathrm{UL}]\end{array}$ & Direct Effect (c') & Total Effect (c) \\
\hline \multirow{5}{*}{ Poster } & $0.19 *(0.036)$ & \multirow{5}{*}{$\begin{array}{l}\text { Response belief } \\
\text { Others' behavior } \\
\text { household level } \\
\text { Commitment } \\
\text { Communication }\end{array}$} & $0.23^{* * *}(0.000)$ & $0.04,[0.01,0.10]$ & & \\
\hline & $0.16(0.185)$ & & $0.07^{* *}(0.019)$ & $0.01,[-0.00,0.04]$ & & \\
\hline & $0.26^{* * *}(0.000)$ & & $0.34^{* * *}(0.000)$ & $0.09,[0.04,0.17]$ & & \\
\hline & $0.46^{* * *}(0.001)$ & & $0.08^{* * *}(0.003)$ & $0.03,[0.01,0.07]$ & & \\
\hline & & & & & $\begin{array}{l}-0.13 \\
(0.083)\end{array}$ & $\begin{array}{c}0.05 \\
(0.542)\end{array}$ \\
\hline \multirow{5}{*}{ Home visit } & $0.22 *(0.016)$ & \multirow{5}{*}{$\begin{array}{l}\text { Response belief } \\
\text { Others' behavior } \\
\text { household level } \\
\text { Commitment } \\
\text { Communication }\end{array}$} & $0.18^{* * *}(0.000)$ & $0.04,[0.01,0.09]$ & & \\
\hline & $0.31 *(0.014)$ & & $0.08 *(0.013)$ & $0.02,[0.01,0.06]$ & & \\
\hline & $0.38^{* * *}(0.000)$ & & $0.40^{* * *}(0.000)$ & $0.16,[0.09,0.25]$ & & \\
\hline & $0.54^{* * *}(0.000)$ & & $0.08^{* * *}(0.001)$ & $0.04,[0.01,0.09]$ & & \\
\hline & & & & & $\begin{array}{l}-0.15^{*} \\
(0.047)\end{array}$ & $\begin{array}{c}0.11 \\
(0.200)\end{array}$ \\
\hline \multirow{5}{*}{ Info sheet } & $-0.09(0.294)$ & \multirow{5}{*}{$\begin{array}{l}\text { Response belief } \\
\text { Others' behavior } \\
\text { household level } \\
\text { Commitment } \\
\text { Communication }\end{array}$} & $0.23^{* * *}(0.000)$ & $-0.02,[-0.07,0.02]$ & & \\
\hline & $0.30 *(0.012)$ & & $0.08 *(0.013)$ & $0.02,[0.01,0.06]$ & & \\
\hline & $0.04(0.518)$ & & $0.31^{* * *}(0.000)$ & $0.01,[-0.02,0.06]$ & & \\
\hline & $0.95^{* * *}(0.000)$ & & $0.06 *(0.017)$ & $0.06,[0.01,0.12]$ & & \\
\hline & & & & & $\begin{array}{c}0.02 \\
(0.796)\end{array}$ & $\begin{array}{c}0.09 \\
(0.244)\end{array}$ \\
\hline
\end{tabular}

Note: ${ }^{*} p \leq 0.05,{ }^{* *} p \leq 0.01,{ }^{* * *} p \leq 0.001$. Displayed are unstandardized betas and $p$-values. Poster: $\mathrm{N}=395$, $R^{2}=0.27(\mathrm{~b})$. Home visit: $\mathrm{N}=394, R^{2}=0.27(\mathrm{~b})$. Info sheet: $N=396, R^{2}=0.25(\mathrm{~b})$. Number of bootstrap samples for bias-corrected bootstrap confidence intervals: 10,000. Level of confidence for all confidence intervals: $95 \%$.

\section{Discussion}

This study aimed to evaluate the activities intended to promote Ebola prevention behaviors. However, it is not only crucial to know whether a promotional activity increased a behavior or not. 
It is equally crucial to understand the reasons for this effect. To achieve this, this study also examined the underlying psychosocial factors to identify which of them were affected by a promotional activity.

\subsection{Psychosocial Factors Influencing EVD Preventive Behaviors}

In line with the findings of several knowledge-attitude-practice (KAP) surveys [5,6], we found that health knowledge about Ebola virus disease (EVD) was significantly associated with the intention not to touch someone who might be suffering from EVD. According to Bandura [28], individuals are more likely to adopt a new behavior if they have greater knowledge about the symptoms of a disease and about the prevention of the disease. In contrast, various other studies have found that factual knowledge is secondary to a range of other factors [14,15,29].

The findings about health knowledge relate to those about the response belief (perceived certainty that a behavior will prevent a disease), which was also a predictor of handwashing with soap and of the intentions to call the Ebola Hotline and not to touch a person who might be suffering from EVD. Jalloh et al. [7] found that handwashing with soap to avoid Ebola infection was mentioned unprompted by $66 \%$ of his sample. Response belief also explained stool-related handwashing in Haiti during the cholera outbreak [20]. However, in this study, response belief is not only the belief that a certain behavior prevents contracting EVD. It is also the belief that the public health infrastructure and system is able to handle the epidemic. Together with commitment, response belief was the most influential factor for the intention to call the Ebola Hotline. This belief is crucial for preventing the spread of a disease such as EVD.

Our findings about health knowledge and response belief are in line with those about perceived vulnerability of the population. The respondents perceived the probability of contracting EVD as high if they did not protect themselves with regular handwashing with soap and water. Additionally, those respondents who thought that they were at risk if they touched a sick person who might have EVD were more likely to have a higher intention not to touch such a person. Jalloh et al. [7] found that the majority of respondents knew that avoiding contact with an infected corpse could prevent Ebola. Whether a perceived threat affects handwashing is consistent with previous research in emergency contexts. Curtis et al. [30] found in their review of motivational, planning, and habitual factors of handwashing in 11 countries that handwashing frequency increased during cholera epidemics (Uganda, Senegal, Kenya, and Peru) and sank again after outbreaks.

Additional findings of our study were that respondents tended to wash hands more often than others did if they perceived that other people around them often wash hands with soap and water and believed that other people important to the respondents expect them to wash their hands. The more the respondents in this study perceived that many people from their own household would call the Ebola Hotline, the higher was their own intention to call the Ebola Hotline. Previous research has shown that norms are highly relevant to handwashing behavior $[19,21,31]$ and other behaviors, including use of deep tube wells [32] and contraceptive methods [33].

The finding that the belief that always washing hands with soap is expensive is associated with handwashing might result from the experience of the respondents that soap has to be purchased more frequently when they perform this behavior continuously.

Commitment was the most important predictor of the intention to call the Ebola Hotline and the intention not to touch a person who might be suffering from EVD. Commitments important for various WASH behaviors in developing countries has been shown by several previous studies [19,22,34,35].

In contrast, the factor commitment to touch explained the intention not to touch a person who might be suffering from EVD. Further analysis showed that 60 respondents, or $12 \%$, of the study participants felt simultaneously committed to not touching and to touching someone who might be suffering from EVD. This might be explained by ambivalence and may be determined by culture and religion. If a respondent said they would not be willing to avoid touching a person who might be suffering from EVD, they were asked to say why not. The most commonly cited reasons included the need, the willingness, and the duty to help the sick person, and the fact that the sick person might be a 
family member, especially a close relative or a child. Similar to these findings, Lee-Kwan et al. [36] found that barriers to safe burials included the perception of bodies that were improperly handled and the fear that stigma may occur if a family member receives a safe, dignified medical burial. This may well explain the wavering between the commitments not to touch and to touch a person who might be suffering from EVD. Nevertheless, this fact could be crucial for preventing or curtailing the spread of EVD and should, therefore, be integrated in promotional activities.

The intention to call the Ebola Hotline was significantly related to communication, which means that people who talked often about the Ebola Hotline tended to have a higher intention to call the Ebola Hotline than others. One-to-one communication plays an essential role in a health behavior change, which has been confirmed by Rimal et al. [26] in their study about cardiovascular disease-related behaviors such as dieting, exercising, and smoking. Winters et al. [8] showed that, in the Ebola outbreak in Sierra Leone, the exposure to information sources was associated with higher knowledge and protective behaviors.

Overall, the models were able to explain a substantial part of the variance of handwashing with soap $(48.5 \%)$ and of the intention to call the Ebola Hotline (27.3\%). Less variance was explained for the intention not to touch a person who might be suffering from EVD (17.1\%), which means that we do not know clearly which psychosocial factors drove this.

\subsection{Effects of Promotional Activities}

The three most effective promotions for handwashing were home visit, poster, and info sheet. Some studies have found positive effects of home visits [37,38], even though, in the study by Contzen and Mosler [20], home visits were negatively associated with handwashing behavior. A study from Thailand [39] found that posters were significantly and positively related with health knowledge but showed a tendency to be negatively related with handwashing behavior, and this was also the case in a study from Haiti [20]. In an analysis of a range of communication channels for promoting hygiene behavior, Pinfold [39] found that printed media such as stickers, posters, and leaflets were associated with significantly higher scores in health knowledge than other channels. However, this positive effect could not be found for behavior. Marais et al. [40] propose a multimethod communication in their eight-step model of health promotion.

In our study, the hygiene kit did not have a significant association with handwashing, nor was it associated with any of the key psychosocial factors. Providing people with infrastructure alone and expecting the target health behavior to occur has been criticized by several authors $[18,41,42]$.

Promotional activities are only successful when they target the key psychosocial factors. The results of this study suggest that all key psychosocial factors mediated the associations of the home visit, the poster, and the info sheet with handwashing. These three promotional activities were effective in tackling handwashing behavior because of the associations between the promotional activities and key psychosocial factors. The hygiene kit was not related to any of the key psychosocial factors and so could not address the behavior. In the main section, the handwashing promotional activities evaluated in this study were very successful in tackling the key psychosocial factors.

The analysis indicated that the promotional activities for calling the Ebola Hotline were significantly related with all the relevant psychosocial factors. Nevertheless, none of the activities were associated with the intention to call the Ebola Hotline. This might be explained by the fact that calling the Ebola Hotline was not a focus of the promotional activities evaluated in this study.

\subsection{Practical Implications}

The findings of this study can serve as a baseline for a further study of handwashing with soap and especially of the intention to call the Ebola Hotline. To change behavior successfully, promotion activities must target those factors that influence behavior. The findings of this study demonstrate that the norm factors, especially others' behavior, response belief, and commitment, emerged as especially relevant to handwashing, the intention to call the Ebola Hotline, and not touching a person who might 
be suffering from EVD. The greater relevance of social norms and other factors than risk factors to health behaviors has been shown in a multi-country review about socio-psychological determinants for safe drinking water consumption behaviors [43].

We found that the home visit, the poster, and the info sheet were successful promotional activities in tackling handwashing behavior because they targeted the key psychosocial factors of handwashing behavior. The RANAS model provides behavior change techniques corresponding to psychosocial factors [44]. To increase handwashing behavior, the five psychosocial factors underlying handwashing with soap have to be tackled. The first of these, others' (dis)approval, can be addressed by giving away stickers that bear a picture of an opinion leader washing his or her hands with soap and water. The second, personal importance, can also be addressed if the stickers mention that people in that household wash their hands with soap at key times and that they are good examples for others such as children. The third factor, others' behavior, may be addressed by a community meeting to increase the perception of what others are doing and by providing participants with a commitment sign to hang up outside their houses. A health worker can inform the participants about their personal risk (conditional vulnerability not protecting) and, together with a doctor from the health facility-others' (dis)approval—explain that handwashing with soap will protect them from EVD and diarrheal diseases (response belief).

For the intention to call the Ebola Hotline, five underlying psychosocial factors need to be targeted. In a radio advert, various kinds of people (others' behavior household) could pledge their intention to call the Ebola Hotline if there is a suspected EVD case in their household (commitment). They believe that this service has to be used to help the affected person and to protect other family members and the members of their community (response belief). At the end of the advert, they ask: "And you, do you also commit yourself to calling the Ebola Hotline if there is a person who might be suffering from Ebola in your household?" (commitment and communication).

\subsection{Limitations}

The results have to be interpreted with caution because studies in an emergency context are especially prone to certain limitations. For ethical reasons, it is not appropriate to use a control group. Therefore, the present study was a cross-sectional study on the factors explaining EVD prevention behaviors and associations between promotional activities, psychosocial factors, and behavior or behavioral intention. However, no conclusions can be drawn about causality.

One limitation is that the interventions implemented by the NGO attracted special attention from the population because of the Ebola outbreak in neighboring countries. Therefore, the impact of the interventions might be smaller when an outbreak is decreasing or even happened long ago.

Another limitation is that we measured the intention of the Ebola-preventing behaviors in a country, which was not directly affected. However, the link between intention and behavior is strong (but not perfect), which has been shown by several studies [45]. Therefore, we can assume that the intention will result in Ebola preventing behaviors.

Measuring handwashing by self-report has been criticized by several scientists [46,47]. However, since the time for the survey was very limited, we could not directly observe handwashing behavior. Therefore, an over-reporting bias for the frequency of handwashing with soap is very likely. It would be useful to include further measurements as proxies $[48,49]$ in the analysis.

In the present study, we did not find relationships between sociodemographic data and behaviors. Seimetz et al. [21] found that self-reported handwashing was not explained by such factors as age, education level, or marital status. Other researchers have suggested that a higher education level and higher age are significantly related to self-reported handwashing frequencies [50,51]. Regarding wealth, studies have found economic status to be significantly associated with hand cleanliness [52], soap availability in the household, and observed handwashing behavior [53,54]. In contrast, Ram et al. [55] found in Senegal that none of their rapid handwashing measures were significantly related to observed handwashing behavior in models including wealth. The same was found in their studies in Peru and 
Vietnam. However, a comparison between studies is difficult. The study by Seimetz et al. [21] into the influence of contextual and psychosocial factors on handwashing did not find wealth to be a predictor of self-reported handwashing frequencies. This means that the psychosocial factors fully explained the effect of wealth on handwashing behavior. Therefore, the authors conclude that hygiene promotions should focus on psychosocial factors rather than sociodemographic factors [21].

The present study focused on psychosocial factors but enabled structural components of a behavioral change to take into account. Future studies should analyze the connection between physical, social, and personal context factors and psychosocial factors in a behavioral change.

The fact that some of the respondents might have experienced several promotional activities and that some combinations might have another effect on behavior than others was not taken into account. Nevertheless, interaction effects should be considered in future studies. We did not integrate the attitudes of the respondents to the various promotional channels and activities in the analyses. Examining attributes of promotions such as its frequency, its likeability, its persuasiveness, and its trustworthiness may be important when evaluating a promotion channel or activity.

\section{Conclusions}

The present study demonstrates that some EVD prevention promotions were associated with the target behavior, and this was because they were associated with the key psychosocial factors steering the behavior. Conversely, promotions that were not associated with the behavior were not associated with the key psychosocial factors. The findings show the important role that psychosocial factors play in prevention behaviors during an EVD outbreak. Behavioral change programs should use evidence to target the right psychosocial factors and, thus, maximize their effects on prevention behaviors, especially in emergency contexts. Social norms and response beliefs were revealed as crucial for the prevention of EVD in the Gambia. However, the RANAS model used in this case focuses only on changes that can be achieved by individuals and households [18]. Changes at other levels, such as the institutional, political, and systemic, are often needed in order to control an outbreak of a contagious disease such as EVD and to influence people's behavior. A situation such as that in West Africa during the last outbreak of EVD requires adequate public health infrastructure, public health resources, and corresponding and culturally appropriate risk communication and health promotion. Different languages and dialects, clear illustrations to include illiterate people, and aspects such as a strong tradition of oral communication and traditional beliefs also have to be considered in the communication [56].

Supplementary Materials: The following are available online at http://www.mdpi.com/1660-4601/16/11/2020/s1, Figure S1: Template of a parallel multiple mediator model.

Author Contributions: Conceptualization, H.-J.M. and A.F.G. Methodology, A.F.G. Validation, J.S. Formal analysis, J.S. Investigation, A.F.G. Resources, H.-J.M. Data curation, J.S. Writing—original draft preparation, A.F.G. Writing-review and editing, H.-J.M. Supervision, H.-J.M. Project administration, H.-J.M. Funding acquisition, H.J.M.

Funding: This research was funded by Oxfam, grant number GLO 009/16.

Acknowledgments: The authors thank the local partner, Concern Universal, and especially Manfred Bojang, Resilience Program Manager at Concern Universal. Many people made the fieldwork for this project possible: several field supervisors, the data collectors, the community leaders, and the community members who participated in the study and shared their time and thoughts with us. Nadja Contzen's friendly review is gratefully acknowledged.

Conflicts of Interest: The authors declare no conflict of interest. The funders had no role in the design of the study, in the collection, analyses, or interpretation of data, in the writing of the manuscript, or in the decision to publish the results. 


\section{Appendix A}

Table A1. Questions to measure the psychosocial factors for handwashing with soap and water.

\begin{tabular}{|c|c|}
\hline Factors & Items \\
\hline \multicolumn{2}{|l|}{ Risk } \\
\hline Community vulnerability & How high do you think is the risk for an average person of your community to get Ebola? \\
\hline Vulnerability & How high do you feel is the risk that you get Ebola? \\
\hline $\begin{array}{l}\text { Conditional vulnerability } \\
\text { not protecting }\end{array}$ & $\begin{array}{l}\text { How likely is it that you get Ebola if you do not protect yourself with regular handwashing with soap } \\
\text { and water at critical moments? }\end{array}$ \\
\hline $\begin{array}{l}\text { Conditional vulnerability } \\
\text { protecting }\end{array}$ & $\begin{array}{l}\text { How likely is it that you get Ebola if you protect yourself with regular handwashing with soap and } \\
\text { water at critical moments? }\end{array}$ \\
\hline & Imagine that you got Ebola, how severe would be the impact on your life in general? \\
\hline Severity & Imagine that you got Ebola, how severe would be the impact on your social life? \\
\hline & Imagine that you got Ebola, how severe would be the impact on your economic situation? \\
\hline Health knowledge & Can people transfer Ebola to others immediately after being infected? \\
\hline \multicolumn{2}{|l|}{ Attitudes } \\
\hline $\begin{array}{l}\text { Beliefs about costs and } \\
\text { benefits (effort) }\end{array}$ & Do you think that always washing hands with soap and water takes a lot of effort? \\
\hline $\begin{array}{l}\text { Beliefs about costs and } \\
\text { benefits (time) }\end{array}$ & How time-consuming do you think is it to always wash hands with soap and water? \\
\hline $\begin{array}{l}\text { Beliefs about costs and } \\
\text { benefits (costs) }\end{array}$ & Do you think that always washing hands with soap and water is expensive? \\
\hline $\begin{array}{l}\text { Beliefs about costs and } \\
\text { benefits (distance) }\end{array}$ & Do you think that the handwashing facility is far away from your usual area of activity? \\
\hline Response belief & $\begin{array}{l}\text { How certain are you that always washing hands with soap and water prevents you and your family } \\
\text { from getting diseases like Ebola or diarrhea? }\end{array}$ \\
\hline Feelings (like) & How much do you like always washing hands with soap and water? \\
\hline \multicolumn{2}{|l|}{ Norms } \\
\hline Others' behavior & How many people in your household always wash hands with soap and water? \\
\hline Others' (dis)approval & $\begin{array}{l}\text { People who are important to you (e.g. your family members, friends, a marabout, imam, other } \\
\text { important people), how much do they approve that you always wash your hands with soap and water? }\end{array}$ \\
\hline Personal importance & How strongly do you feel a personal obligation to yourself to always wash hands with soap and water? \\
\hline \multicolumn{2}{|l|}{ Abilities } \\
\hline How-to-do knowledge & How did the person wash her/his hands? (observation) \\
\hline Confidence in performance & How sure are you that you can always wash your hands with soap and water? \\
\hline $\begin{array}{l}\text { Confidence in } \\
\text { performance (water) }\end{array}$ & How difficult is it to get as much water as you need to always wash hands with soap and water? \\
\hline $\begin{array}{l}\text { Confidence in } \\
\text { performance (soap) }\end{array}$ & How difficult is it to get as much soap as you need to always wash hands with soap and water? \\
\hline $\begin{array}{l}\text { Confidence in } \\
\text { performance (time) }\end{array}$ & How difficult is it to find the time to wash hands with soap and water? \\
\hline $\begin{array}{l}\text { Confidence in } \\
\text { performance (distance) } \\
\text { Confidence in continuation }\end{array}$ & $\begin{array}{l}\text { How confident are you that you can wash hands with soap and water, even if you have to walk some } \\
\text { distance to reach the next handwashing facility? } \\
\text { How confident are you that you can wash hands with soap and water, even if urgent tasks arise that } \\
\text { interfere with hand washing? }\end{array}$ \\
\hline \multicolumn{2}{|l|}{ Self-Regulation } \\
\hline $\begin{array}{l}\text { Coping planningAction } \\
\text { controlAction planning }\end{array}$ & $\begin{array}{l}\text { Do you have a plan on what to do so that you always have water for hand washing? Please specify. } \\
\text { Do you have a plan on what to do so that you always have soap for hand washing? Please specify. } \\
\text { Do you have a plan on what to do when there is no soap for hand washing? Please specify. } \\
\text { How much control do you have over whether you can always wash your hands with soap and water? } \\
\text { How much do you pay attention to ensure you always have enough soap at home to wash hands with } \\
\text { soap and water? }\end{array}$ \\
\hline Remembering & $\begin{array}{l}\text { When you think about the last } 24 \text { h: How often did it happen that you intended to wash hands with } \\
\text { soap and water and then forgot to do so? } \\
\text { In your family, do you ever remind each other to wash hands with soap and water? } \\
\text { How committed do you feel to wash hands with soap and water? }\end{array}$ \\
\hline Commitment & $\begin{array}{l}\text { How important is it for you to wash hands with soap and water? } \\
\text { How annoyed do you feel if you forgot to wash hands with soap and water? }\end{array}$ \\
\hline Communication & $\begin{array}{l}\text { How often do you talk about the Ebola Hotline and how you can call it if you may have a suspected } \\
\text { case of Ebola in your household? }\end{array}$ \\
\hline
\end{tabular}

Notes. Response scales range from 1-5, 1 indicates the lowest value on the scale, and 5 represents the highest value on the scale ( $1=$ not at all, $2=$ a little, $3=$ medium, $4=$ strongly, $5=$ very strongly). For health knowledge, a sum score of the correct answers was calculated. Equivalent items are present for calling the Ebola Hotline and not touching a sick person. 
Table A2. Linear regression analysis for demographic variables explaining handwashing, the intention to call the Ebola Hotline and report a suspected EVD case, and the intention to not touch someone who might be suffering from EVD.

\begin{tabular}{ccccc}
\hline Variables & Behavior & Handwashing & Calling the Hotline & Not Touching \\
\hline Gender & Scale & $\boldsymbol{\beta}$ & $\boldsymbol{\beta}$ & $\boldsymbol{\beta}$ \\
\hline Age in years & Female/Male & -0.423 & -0.012 & -0.056 \\
Household size & & -0.128 & 0.023 & -0.088 \\
Marital status & Married/ others 1-0 & 0.057 & 0.078 & 0.078 \\
Literacy & Yes/ No & 0.018 & $0.144^{*}$ & 0.057 \\
Education & Yes/No & $-0.176^{*}$ & $0.150^{*}$ & $0.244^{* * *}$ \\
Religion & Muslims /others 1-0 & $0.173^{*}$ & $0.167^{*}$ & 0.086 \\
Income & 1-6 (categories increase.) & -0.202 & 0.010 & 0.115 \\
\hline
\end{tabular}

Notes. ${ }^{*} p \leq 0.05,{ }^{* *} p \leq 0.01,{ }^{* * *} p \leq 0.001 . \mathrm{N}=201$, Adjusted $\mathrm{R}^{2}$ for handwashing $=0.072$. Adjusted $\mathrm{R}^{2}$ for calling the Hotline $=0.022$.

\section{References}

1. WHO. Ebola Situation Reports. Available online: http://apps.who.int/ebola/current-situation/ebola-situationreport-30-march-2016 (accessed on 1 June 2019).

2. WHO. Ebola Virus Disease. Available online: http://www.who.int/mediacentre/factsheets/fs103/en/ (accessed on 1 June 2019).

3. Henao-Restrepo, A.M.; Longini, I.M.; Egger, M.; Dean, N.E.; Edmunds, W.J.; Camacho, A.; Carroll, M.W.; Doumbia, M.; Draguez, B.; Duraffour, S.; et al. Efficacy and effectiveness of an rVSV-vectored vaccine expressing Ebola surface glycoprotein: Interim results from the Guinea ring vaccination cluster-randomised trial. Lancet 2015, 386, 857-866. [CrossRef]

4. Bausch, D.G.; Schwarz, L. Outbreak of Ebola virus disease in Guinea: Where ecology meets economy. PLoS Negl. Trop. Dis. 2014, 8, e3056. [CrossRef] [PubMed]

5. Nyakarahuka, L.; Skjerve, E.; Nabadda, D.; Sitali, D.C.; Mumba, C.; Mwiine, F.N.; Lutwama, J.J.; Balinandi, S.; Shoemaker, T.; Kankya, C. Knowledge and attitude towards Ebola and Marburg virus diseases in Uganda using quantitative and participatory epidemiology techniques. PLoS Negl. Trop. Dis. 2017, 11, e0005907. [CrossRef] [PubMed]

6. Jalloh, M.F.; Robinson, S.J.; Corker, J.; Li, W.; Irwin, K.; Barry, A.M.; Ntuba, P.N.; Diallo, A.A.; Jalloh, M.B.; Nyuma, J. Knowledge, attitudes, and practices related to Ebola virus disease at the end of a National Epidemic-Guinea, August 2015. MMWR Morb. Mortal. Wkly. Rep. 2017, 66, 1109-1115. [CrossRef] [PubMed]

7. Jalloh, M.F.; Sengeh, P.; Monasch, R.; Jalloh, M.B.; DeLuca, N.; Dyson, M.; Golfa, S.; Sakurai, Y.; Conteh, L.; Sesay, S. National survey of Ebola-related knowledge, attitudes and practices before the outbreak peak in Sierra Leone: August 2014. BMJ Glob. Health 2017, 2, e000285. [CrossRef] [PubMed]

8. Winters, M.; Jalloh, M.F.; Sengeh, P.; Jalloh, M.B.; Conteh, L.; Bunnell, R.; Li, W.; Zeebari, Z.; Nordenstedt, H. Risk Communication and Ebola-Specific Knowledge and Behavior during 2014-2015 Outbreak, Sierra Leone. Emerg. Infect. Dis. 2018, 24, 336-344. [CrossRef] [PubMed]

9. Aboud, F.E.; Singla, D.R. Challenges to changing health behaviours in developing countries: A critical overview. Soc. Sci. Med. 2012, 75, 589-594. [CrossRef]

10. Vujcic, J.; Ram, P.K.; Blum, L.S. Handwashing promotion in humanitarian emergencies: Strategies and challenges according to experts. J. Water Sanit. Hyg. Dev. 2015, 5, 574-585. [CrossRef]

11. Davidson, K.W.; Goldstein, M.; Kaplan, R.M.; Kaufmann, P.G.; Knatterud, G.L.; Orleans, C.T.; Spring, B.; Trudeau, K.J.; Whitlock, E.P. Evidence-based behavioral medicine: What is it and how do we achieve it? Ann. Behav. Med. 2003, 26, 161-171. [CrossRef]

12. Michie, S.; Abraham, C. Interventions to change health behaviours: Evidence-based or evidence-inspired? Psychol. Health 2004, 19, 29-49. [CrossRef]

13. Rhoads, S.J.; Bush, E.; Haselow, D.; Vyas, K.S.; Wheeler, J.G.; Faulkner, A.; Lowery, C. Mobilizing a statewide network to provide Ebola education and support. Telemed. e-Health 2016, 22, 153-158. [CrossRef] [PubMed] 
14. Biran, A.; Schmidt, W.P.; Wright, R.; Jones, T.; Seshadri, M.; Isaac, P.; Nathan, N.; Hall, P.; McKenna, J.; Granger, S. The effect of a soap promotion and hygiene education campaign on handwashing behaviour in rural India: A cluster randomised trial. Trop. Med. Int. Health 2009, 14, 1303-1314. [CrossRef] [PubMed]

15. Hoque, B.A.; Juncker, T.; Sack, R.; Ali, M.; Aziz, K. Sustainability of a water, sanitation and hygiene education project in rural Bangladesh: A 5-year follow-up. Bull. World Health Organ. 1996, 74, 431. [PubMed]

16. Contzen, N.; Mosler, H.-J. Methodological Fact Sheet: The RANAS Approach to Systematic Behavior Change. Available online: http://www.eawag.ch/fileadmin/Domain1/Abteilungen/ess/projekte/EHPsy/ Methodological_Fact_Sheets.pdf (accessed on 1 June 2019).

17. Abraham, C.; Abraham, C.; Kools, M. Mapping change mechanisms onto behaviour change techniques: A systematic approach to promoting behaviour change through text. In Writing Health Communication: An Evidence-Based Guide; SAGE Publications Ltd: London, UK, 2012; pp. 99-116.

18. Mosler, H.-J. A systematic approach to behavior change interventions for the water and sanitation sector in developing countries: A conceptual model, a review, and a guideline. Int. J. Environ. Health Res. 2012, 22, 431-449. [CrossRef] [PubMed]

19. Contzen, N.; Mosler, H.-J. Identifying the psychological determinants of handwashing: Results from two cross-sectional questionnaire studies in Haiti and Ethiopia. Am. J. Infect. Control 2015, 43, 826-832. [CrossRef]

20. Contzen, N.; Mosler, H.-J. Impact of different promotional channels on handwashing behaviour in an emergency context: Haiti post-earthquake public health promotions and cholera response. J. Public Health 2013, 21, 559-573. [CrossRef]

21. Seimetz, E.; Boyayo, A.-M.; Mosler, H.-J. The Influence of Contextual and Psychosocial Factors on Handwashing. Am. J. Trop. Med. Hyg. 2016, 94, 1407-1417. [CrossRef]

22. Sonego, I.L.; Mosler, H.-J. Why are some latrines cleaner than others? Determining the factors of habitual cleaning behaviour and latrine cleanliness in rural Burundi. J. Water Sanit. Hyg. Dev. 2014, 4, 257-267. [CrossRef]

23. Contzen, N.; Meili, I.H.; Mosler, H.-J. Changing handwashing behaviour in southern Ethiopia: A longitudinal study on infrastructural and commitment interventions. Soc. Sci. Med. 2015, 124, 103-114. [CrossRef]

24. Hoffmeyer-Zlotnik, J.H. New sampling designs and the quality of data. In Developments in Applied Statistics; FDV Methodoloski zvezki: Ljubljana, Slovenia, 2003; pp. 205-217.

25. Rogers, E.M. Diffusion of Innovations; Simon and Schuster: New York, NY, USA, 2010.

26. Rimal, R.N.; Flora, J.A.; Schooler, C. Achieving improvements in overall health orientation effects of campaign exposure, information seeking, and health media use. Commun. Res. 1999, 26, 322-348. [CrossRef]

27. Hayes, A.F. PROCESS: A Versatile Computational Tool for Observed Variable Mediation, Moderation, and Conditional Process Modeling; University of Kansas: Lawrence, KS, USA, 2012.

28. Bandura, A. Health promotion by social cognitive means. Health Educ. Behav. 2004, 31, 143-164. [CrossRef]

29. Contzen, N.; Inauen, J. Social-cognitive factors mediating intervention effects on handwashing: A longitudinal study. J. Behav. Med. 2015, 38, 956-969. [CrossRef] [PubMed]

30. Curtis, V.; Danquah, L.; Aunger, R. Planned, motivated and habitual hygiene behaviour: An eleven country review. Health Educ. Res. 2009, 24, 655-673. [CrossRef] [PubMed]

31. Aunger, R.; Schmidt, W.-P.; Ranpura, A.; Coombes, Y.; Maina, P.M.; Matiko, C.N.; Curtis, V. Three kinds of psychological determinants for hand-washing behaviour in Kenya. Soc. Sci. Med. 2010, 70, 383-391. [CrossRef] [PubMed]

32. Mosler, H.-J.; Blöchliger, O.R.; Inauen, J. Personal, social, and situational factors influencing the consumption of drinking water from arsenic-safe deep tubewells in Bangladesh. J. Environ. Manag. 2010, 91, 1316-1323. [CrossRef]

33. Fekadu, Z.; Kraft, P. Expanding the theory of planned behaviour: The role of social norms and group identification. J. Health Psychol. 2002, 7, 33-43. [CrossRef] [PubMed]

34. Inauen, J.; Tobias, R.; Mosler, H.-J. Predicting water consumption habits for seven arsenic-safe water options in Bangladesh. BMC Public Health 2013, 13, 417. [CrossRef] [PubMed]

35. Huber, A.C.; Mosler, H.-J. Determining behavioral factors for interventions to increase safe water consumption: A cross-sectional field study in rural Ethiopia. Int. J. Environ. Health Res. 2013, 23, 96-107. [CrossRef] [PubMed]

36. Lee-Kwan, S.H.; DeLuca, N.; Bunnell, R.; Clayton, H.B.; Turay, A.S.; Mansaray, Y. Facilitators and barriers to community acceptance of safe, dignified medical burials in the context of an Ebola epidemic, Sierra Leone, 2014. J. Health Commun. 2017, 22, 24-30. [CrossRef] 
37. Agha, S.; Van Rossem, R. Impact of mass media campaigns on intentions to use the female condom in Tanzania. Int. Fam. Plan. Perspect. 2002, 28, 151-158. [CrossRef]

38. Hussain, A.; Aaro, L.E.; Kvale, G. Impact of a health education program to promote consumption of vitamin A rich foods in Bangladesh. Health Promot. Int. 1997, 12, 103-109. [CrossRef]

39. Pinfold, J.V. Analysis of different communication channels for promoting hygiene behaviour. Health Educ. Res. 1999, 14, 629-639. [CrossRef] [PubMed]

40. Marais, F.; Minkler, M.; Gibson, N.; Mwau, B.; Mehtar, S.; Ogunsola, F.; Banya, S.S.; Corburn, J. A community-engaged infection prevention and control approach to Ebola. Health Promot. Int. 2015, 31, 440-449. [CrossRef] [PubMed]

41. Cairncross, S.; Shordt, K. It does last! Some findings from a multi-country study of hygiene sustainability. Waterlines 2004, 22, 4-7. [CrossRef]

42. Sonego, I.L.; Huber, A.C.; Mosler, H.-J. Does the implementation of hardware need software? A longitudinal study on fluoride-removal filter use in Ethiopia. Environ. Sci. Technol. 2013, 47, 12661-12668. [CrossRef]

43. Lilje, J.; Mosler, H.-J. Socio-psychological determinants for safe drinking water consumption behaviors: A multi-country review. J. Water Sanit. Hyg. Dev. 2017, 7, 13-24. [CrossRef]

44. Mosler, H.-J.; Contzen, N. ESI 3.1: Catalog of Behavior Change Techniques (BCTs). Available online: https://www.eawag.ch/fileadmin/Domain1/Abteilungen/ess/schwerpunkte/ehpsy/publ/Guideline/ ESI_3.1_Catalog_of_behavior_change_techniques_BCTs_pdf (accessed on 1 June 2019).

45. Armitage, C.J.; Conner, M. Efficacy of the theory of planned behaviour: A meta-analytic review. Br. J. Soc. Psychol. 2001, 40, 471-499. [CrossRef]

46. Biran, A.; Rabie, T.; Schmidt, W.; Juvekar, S.; Hirve, S.; Curtis, V. Comparing the performance of indicators of hand-washing practices in rural Indian households. Trop. Med. Int. Health 2008, 13, 278-285. [CrossRef]

47. Ram, P. Practical Guidance for Measuring Handwashing Behavior: 2013 Update. Available online: https://www.wsp.org/sites/wsp/files/publications/WSP-Practical-Guidance-Measuring-HandwashingBehavior-2013-Update.pdf (accessed on 1 June 2019).

48. Ruel, M.T.; Arimond, M. Spot-check observational method for assessing hygiene practices: Review of experience and implications for programmes. J. Health Popul. Nutr. 2002, 20, 65-76.

49. Contzen, N.; De Pasquale, S.; Mosler, H.J. Over-Reporting in Handwashing Self-Reports: Potential Explanatory Factors and Alternative Measurements. PLoS ONE 2015, 10, e0136445. [CrossRef]

50. Tüzün, H.; Karakaya, K.; Deniz, E.B. Turkey Handwashing Survey: Suggestion for taking the ecological model into better consideration. Environ. Health Prev. Med. 2015, 20, 325-331. [CrossRef] [PubMed]

51. Tao, S.; Cheng, Y.; Lu, Y.; Hu, Y.; Chen, D. Handwashing behaviour among Chinese adults: A cross-sectional study in five provinces. Public Health 2013, 127, 620-628. [CrossRef] [PubMed]

52. Halder, A.K.; Tronchet, C.; Akhter, S.; Bhuiya, A.; Johnston, R.; Luby, S.P. Observed hand cleanliness and other measures of handwashing behavior in rural Bangladesh. BMC Public Health 2010, 10, 545. [CrossRef] [PubMed]

53. Luby, S.P.; Halder, A.K. Associations among handwashing indicators, wealth, and symptoms of childhood respiratory illness in urban Bangladesh. Trop. Med. Int. Health 2008, 13, 835-844. [CrossRef] [PubMed]

54. Ram, P.K.; Halder, A.K.; Granger, S.P.; Jones, T.; Hall, P.; Hitchcock, D.; Wright, R.; Nygren, B.; Islam, M.S.; Molyneaux, J.W. Is structured observation a valid technique to measure handwashing behavior? Use of acceleration sensors embedded in soap to assess reactivity to structured observation. Am. J. Trop. Med. Hyg. 2010, 83, 1070-1076. [CrossRef] [PubMed]

55. Ram, P.; Sahli, M.; Arnold, B.; Colford, J.; Chase, C.; Briceno, B.; Orsola-Vidal, A.; Gertler, P. Validity of Rapid Measures of Handwashing Behavior: An Analysis of Data from Multiple Impact Evaluation in the Global Scaling Up Handwashing Project. In Water and Sanitation Program: Technical Paper; The World Bank: Washington, DC, USA, 2014.

56. Bedrosian, S.R. Lessons of Risk Communication and Health Promotion-West Africa and United States. MMWR Suppl. 2016, 65, 68-74. [CrossRef] [PubMed]

(C) 2019 by the authors. Licensee MDPI, Basel, Switzerland. This article is an open access article distributed under the terms and conditions of the Creative Commons Attribution (CC BY) license (http://creativecommons.org/licenses/by/4.0/). 